POCKET REFERENCE GUIDE TO MEDICAL MICROBIOLOGY By

Frank B. Engley. (Pp. xii +338 ; illustrated. 35s.)

London: J. \& A. Churchill Ltd. 1963.

This small paperback, which comes from Missouri, is packed with information in very small print covering all microbes from helminths to viruses and animal hosts from men to mice. There are numerous tables including one which interprets abbreviations and another with Greek and Latin prefixes and suffixes. Techniques are demonstrated by line drawings. No serious misprints or errors were discovered. Despite the author's disapproval of cramming this is an obvious use for this book. It would be invaluable to anyone wishing to set or solve microbiological crossword puzzles.

E. JOAN STOKES

BIOCHEMiCAL VALUES IN CLINICAL MEDiCINe, 2nd ED. By R. D. Eastham (Pp. iv + 160. 15s.) Bristol: John Wright and Sons. 1963.

Biochemical tests, and our knowledge of how their results vary in disease, have multiplied so rapidly that it is no longer possible to carry in one's head all the latest information on normal and abnormal values, so Dr. Eastham's pocket book fills a real need and its success is shown by the number of clinicians and laboratory workers of all degrees of seniority whose pockets bulge with the first edition.

In this new edition the alphabetical arrangement has been improved, in particular the subheadings under each section. About nine sections have been deleted and double that number of new ones added, but there has been only a $10 \%$ increase in length. Most of the new sections deal with estimations of enzymes. Other new sections include one on blood carbon dioxide (better abbreviated to $\mathrm{PcO}_{2}$ than $\mathrm{pcO}_{2}$ ). In this and the section on $p \mathrm{H}$ the convenience of the new methods using capillary blood might be worth mentioning.

This little book is so complete that the clinician should be reminded somewhere, even if only in the preface, that there are two other aspects of the subject which he should take into account, namely, the technical errors of the estimations done in his hospital laboratory and the relative time required and skill needed for the different estimations.

As this is a pocket book a few blank pages added at the end would be very useful for noting additions, corrections, and references. There are inevitably some errors and misprints, but these are few in number.

\section{GREGOR GRANT}

THE BIOCHEMICAL DIAGNOSIS OF HEART DISEASE By C. M.

Agress \& H.M. Estrin. (Pp. xx + 173. \$7.75) Springfield, Illinois: Charles C. Thomas. 1963.

This small book, as specifically stated on the cover, is written for the cardiologist, internist (houseman), and practising physician.

The first two-thirds of the book are concerned with the use of enzymes in the diagnosis of heart disease with descriptions of, and suggested reasons for, the various enzyme changes found in myocardial infarction and other disease states which can confuse the diagnosis. Although pathologists may regret that in a book published only last year the old terminology-D.P.N., ketoglutarate-is still used, they will find this section both useful and interesting.

The last third of the book is entitled 'Other biochemical tests in heart disease'. Each disease, however rare, is considered separately with the laboratory findings, haematological and bacteriological as well as chemical, usually associated with it. The final chapter covers electrolyte and body water in only 11 pages and is of necessity very scamped. This last part of the book is aimed completely at cardiologists, I think, but pathologists may occasionally find it of use.

\section{EUNICE LOCKEY}

NEUROMETABOLIC DISORDERS IN CHILDHOOD Proceedings of Symposium in Sheffield in May 1963. Edited by K. S. Holt and J. Milner, (Pp. vii + 111; illustrated. 15s.) Edinburgh and London: E. \& S. Livingstone. 1963.

This book comprises the proceedings of a symposium held at the University of Sheffield in May 1963. Mental subnormality is becoming of increasing importance in paediatrics and the elucidation of neurometabolic disorders offers hope for treatment. In his concluding remarks, Professor C. E. Dent pointed out that 'rare diseases have now become quite common', and he laid stress on the need for early diagnosis.

From such a vast subject, some individual topics were selected for detailed discussion and the authoritative chapters on 'Neuropathological changes in diseases caused by inborn errors of metabolism'; 'A follow-up study of galactosaemic cases', 'Liver involvement in Wilson's disease and the other disorders of copper storage'; and 'Maple syrup urine disease' are particularly good accounts of the present state of knowledge.

The book is nicely produced, but unfortunately has no index. It should prove useful also to clinicians who, though not directly working in this field, require up-todate summaries of individual metabolic disorders dealt with in this book.

B. CLAYTON

PATHOLOGY OF TUMOURS OF THE NERVOUS SYSTEM, 2nd ED.

Chapter by C. E. Lumsden. By D. S. Russell and L. J.

Rubinstein. (Pp. 345; 314 figures. 70s.) London: Edward Arnold (Publishers) Ltd., 1963.

This book is divided into two parts. The first and by far the larger part is in effect a systematic analysis of observations made with the naked eye or from frozen and paraffin sections over more than 60 years. The authors' experience and material have an important place in this analysis. While the classifications and interpretations have naturally not yet obtained universal acceptance, the popularity of the first edition indicates general appreciation of it as a practical and clinically acceptable guide to diagnosis which had long been awaited. Progress in a field which has been open so long is bound to be slow and it is not surprising that in the second edition this part only differs in minor respects from the first, though a description of the pituitary adenomas is a welcome addition.

This first part forms a firm foundation upon which the second can rest. This, by Professor Lumsden, concerns tissue culture. In a masterly and restrained analysis of a 
rapidly developing field to which he has himself contributed much, he is able to demonstrate the value of tissue culture in dispelling undue rigidity in concepts of tumour genesis based exclusively on histological sections. He has once again succeeded in indicating the growth and vitality of a subject which many have regarded as largely worked out. It is to be hoped that his stimulating chapter will encourage others well versed in conventional neuropathology to take up the many new techniques now available so that still more new light may be shone on old facts.

A. L. WOOLF

TUMOURS OF THE SKIN A collection of papers presented at the 7th Annual Clinical Conference on Cancer, 1962, at the University of Texas, M.D. Anderson Hospital and Tumour Institute, Houston, Texas. (Pp. 322.) Book Medical Publishers Inc. 1964.

There are fringe benefits in our cloudy skies and contaminated air. In Texas, $24 \%$ of cancer is skin cancer, one third of which is squamous cell carcinoma, nearly all on unprotected skin. 'Tumours of the skin' reflects this great experience and covers epidemiological, diagnostic, and therapeutic aspects. Pathologists will be interested in the papers on precancerous lesions and the aetiological and genetic factors but the main theme is clinical diagnosis and management. There is not much that is really new in this book, and as it is neither greatly stimulating nor designed for reference, it seems unlikely to have a wide appeal.

R. A. B. DRURY

THE CHEST FILM IN MASSIVE PULMONARY EMBOLISM By Daniel J. Torrance. (Pp. 74; 31 figures; illustrated.

\$6.75.) Springfield, Illinois: Charles C. Thomas. 1963. This monograph covers the $x$-ray diagnosis of massive pulmonary artery occlusion based principally on the plain $x$-ray film of the chest. The subject is of increasing importance with the possibility of prompt surgical treatment of the condition by embolectomy in conjunction with cardiopulmonary bypass. Most patients do not succumb instantly to massive pulmonary embolism; many survive for many hours. Plainly, however, speed in diagnosis is essential for successful surgery, and any aid the radiologist can give to the clinician by simple radiography is of the greatest value.

The work is based on 23 case presentations, all of which are fully documented and illustrated with the original radiographs and diagrams of the pulmonary arteries, as found at necropsy. Other associated findings such as pulmonary infarction, atelectatic changes, and hyperaeration of the lung are also discussed. The general standard of compilation is excellent and the diagrams are of a very high order. The radiographs are sometimes not as clear as they could be, but many of the originals were of necessity taken on portable apparatus? The author does not deal with pulmonary arteriography which has a place in the management of these cases when? diagnosis is doubtful.

Dr. Torrance is to be congratulated on an excellents and timely publication when it appears that a new periodo of more active therapy for massive pulmonary embolismo is arriving.

GLYN LLOYD

HAEMATOLOGICAL TECHNIQUE FOR MEDICAL LABORATORY TECHNICIANS AND MEDICAL STUDENTS 3rd ed. By E. M ڤ Darmady and S. G. T. Davenport. (Pp. viii $+263 ;$ 22 figures: 4 colour plates; 16 tables. 30s.) London: J. \& A. Churchill L.td. (1963).

This is the third edition of a book on haematologicalo techniques for medical laboratory technicians and medical students. The senior author is an experienced pathologist who has an intimate knowledge of hospital laboratory $\vec{v}$ methods. His former chief laboratory technician is the? co-author.

The main object of the book is to present thosec haematological techniques which have proved to be ${ }^{\complement}$ most useful in the diagnostic hospital laboratory service.. Instead of producing a technical manual the authors have- chosen to widen the presentation. Thus whilst the $Z$ technical methods are highlighted, the background has been filled in with short clinical and pathological $\frac{\Phi}{3}$ descriptions. This helps to round off and give significance to the whole.

The introductory chapter describes the process of $\overrightarrow{0}$ haemopoiesis in a most succinct way. The later chapteis present a logical approach to the laboratory investgations likely to be helpful in the various disorders of the blood. The chosen laboratory methods are each presented in such a way that they can be followed by the most junior member of the laboratory staff.

The presentation and printing of the book are excellent. It is written in a clear, concise, and readable style.

There are some who are not in sympathy with a combination of theoretical text and laboratory manual. 3 In such a book the main problem is where to introduce the laboratory method into the descriptive text. Just as? for various reasons no classification of disorders of the blood is entirely satisfactory, so also is it difficult to? associate the technical method with what everyone would $\overline{0}$ regard as the most appropriate clinical condition. It is this personal bias in selection that has led to a book in $\delta$ which the technical methods are collected together in an appendix.

This book on haematological techniques has individuality, a terse style, and clear technical descriptions. $\frac{7}{0}$ It will find its way onto the bench and into the library of many haematological departments.

G. M. NELSON 